\title{
EL PLANEAMIENTO URBANÍSTICO, DE LA SEGURIDAD A LA INCERTIDUMBRE
}

\author{
Marian Leboreiro Amaro (Dra. Arquitecta - Profesora titular DUyOT)
}

Al iniciar mi vida profesional, nada más lejos de mí que dedicarme al planeamiento, a la ciudad sí. Desde que naces formas parte de ella y en ella te mueves y moldea tus intereses como un medio más de los que te rodean y al que el arquitecto se incorpora en su construcción. Por otra parte de caer en la tentación, no había más que un texto con el que trabajar, la Ley del Suelo de 1975, a la que Larrodera nos había introducido con su natural competencia y unos reglamentos que aprender, nada que un curso en la Escuela de Práctica Jurídica no pudiese resolver. Textos claros y contundentes, jurídicamente comprensibles y de fácil aplicación. Un Estado centralizado y unas competencias claras.

Dicho esto habrá que explicar e intentar comprender que es lo que ha ocurrido. Cuando apenas habían pasado unos años de actividad profesional, con planeamiento en ejecución, de repente nos vimos sumidos en la mayor incertidumbre y aún no había empezado la judicialización de unos documentos que, en principio y ateniéndose a las reglas no podían presentar mayor complicación. Una buena cartografía, no siempre era así, un buen conocimiento del lugar a través de un trabajo de campo en profundidad, unos criterios y objetivos bien definidos por los políticos, tampoco era siempre así, pero a los técnicos aún se les escuchaba.

El trabajo en conjunto iba surgiendo y se matizaba con el contacto con los vecinos y sus aportaciones; ellos eran y siguen siendo los auténticos conocedores de sus problemas y necesidades, aún cuando casi siempre vigilando su propio interés, pero escuchaban y permitían aprender juntos. Rápidamente los contactos se fueron perdiendo, la clase política fue teniendo constancia de sus prerrogativas y la participación reglada, formal, prevista en la ley se consideró suficiente.

Un análisis y un diagnóstico, un modelo definido y consensuado y la utilización de las herramientas legales, la panoplia de instrumentos de la que hablaba Eduardo Mangada, y en las que todos, en mayor o menor media confiábamos, bastaban para que el documento tomase forma, en un momento en el que el planeamiento científico ya se ponía en duda ante la complejidad de un mundo que comenzaba a cambiar rápidamente y en el que sucesivas crisis obligaban a repensarlo todo.

No se puede decir que la llegada de las autonomías y la transferencia de competencias en materia urbanística, tuviese consecuencias en el método de trabajo ni en la defensa de la seguridad jurídica, se asumía un marco aceptado para el desarrollo de la actividad urbanística. Por otra parte, no era difícil entender que cada territorio tenía sus peculiaridades propias y que acercarse a ellas y asumirlas suponía una oportunidad para el territorio y para nuestras ciudades.

Puede decirse que, al menos de mi experiencia personal, hasta que la Sentencia del Tribunal Constitucional, 61/1997 que trastoca el orden establecido, todo discurría dentro de la normalidad, las legislaciones se habían ido adaptado en las distintas comunidades y eran pocas las legislaciones propias, continuaba la inercia, que aún 
continua, al aceptar la validez de los Reglamentos de Planeamiento, Gestión y Disciplina del 1978, siempre y cuando no contradigan las nuevas leyes.

La Sentencia supuso un punto de inflexión y abrió la espita que condujo a una legislación propia en cada Comunidad, aún cuando más de una asumió la legislación contestada.

La entrada en la Unión Europea, en principio sin consecuencias al no tener ésta competencias en materia de territorio ni urbanística, fue poco a poco incidiendo y exigiendo adaptaciones, a veces de fuerte calado como la trasposición de la Directiva 2001/42/CE.

Para entonces el panorama había cambiado con España ya incorporada a los países plenamente desarrollados. En el país la competitividad económica empieza a adquirir relevancia y pronto se traslada, al igual que en otros países de su entorno, a la competitividad entre ciudades, a la necesidad de su posicionamiento y desarrollo. Una plena incorporación al estado del bienestar, un mayor nivel de renta y una mayor formación de sus ciudadanos, conlleva nuevos hábitos, formas de comportamiento y nuevas demandas ya sea en equipamientos y servicios o nuevas tipologías de vivienda.

Todo ello, junto con cambios en el sistema financiero, terminará conduciendo a una alteración o alza del precio del suelo y de la vivienda que en su momento lleva a la redacción de la Ley estatal 6/1998, de 13 de abril, sobre régimen del suelo y valoraciones y el Real Decreto Ley 4/2000, de medidas urgentes de liberalización en el sector inmobiliario y de transportes, en la pretensión de que una mayor cantidad de suelo conduciría a la bajada de los precios. Pronto se demostró que eso no era así, pero no obstante se desencadenó la adaptación de la legislación autonómica. Se había producido un primer cambio, que no tardaría en convertirse en una catarata legislativa, que nos ha conducido a que en el momento presente, a la espera de nuevas modificaciones manejemos textos consolidados en sucesivas ediciones de la legislación urbanística, véanse los caso de Madrid y Galicia, caso este último sobre el que me gustaría incidir.

Ambas comunidades parten de dos leyes con idéntica numeración con un año de diferencia la 9/2001 de Madrid y la 9/2002 en Galicia. Desde el 2002 ambas han sufrido múltiples modificaciones, algunas de gran calado y de difícil justificación más allá de razones coyunturales. En el caso de Madrid se acumulan 12 modificaciones con una prevalencia de las realizadas a través de las Leyes de medidas fiscales y administrativas, que han de entenderse ajenas a cuestiones urbanísticas y vinculadas a situaciones de otra índole, básicamente económicas. En Galicia son 11, en este caso se trata de leyes en paralelo utilizándose solo una Ley de Medidas Fiscales y Administrativas en el 2010. No es un fenómeno que no se tenga en cuenta y no preocupe, así la exposición de motivos del Texto Refundido de la Ley sobre Régimen del Suelo de 2008, ya se hace eco de lo preocupante de la situación.

En el caso de Galicia, y con anterioridad a la legislación urbanística vigente, apareció la Ley 10/1995, de 23 de noviembre, de ordenación del territorio de Galicia, escasamente utilizada excepción hecha de los planes sectoriales nacidos para resolver conflictos puntuales de incidencia supramunicipal o atender a políticas de vivienda 0 de previsión de parques empresariales. 
Los documentos producidos de mayor relieve son las Directrices de Ordenación del Territorio, su larga tramitación desvirtuó su contenido y alcance. Se trata de un documento indicativo, sin determinaciones estructurantes para influir en el territorio, más allá de una jerarquización del mismo, incluye unas normas orientativas y excluyentes, lo que obliga a acudir a ellas en la elaboración del planeamiento urbanístico.

El otro documento es el Plan de Ordenación del Litoral, tiene más el carácter de un documento de investigación de lo ocurrido y control para los planeamientos urbanísticos sobre los que se impone, con un escaso valor normativo y más dirigido a un reconocimiento paisajístico conducente a la elaboración de una estrategia de paisaje en marcha. El POL no será de aplicación en los suelos urbanos y de núcleo rural reconocidos por el planeamiento, en la línea de la Ley de Costas.

La ley 9/2002 de Ordenación Urbanística y Protección del Medio Rural de Galicia (en adelante LOUG), hoy vigente con modificaciones sucesivas, se aprueba como modificación de la de 1997, justificándose su necesidad en la aprobación de la Ley estatal 6/1998, de 13 de abril, sobre régimen del suelo y valoraciones y el Real Decreto Ley 4/2000, de medidas urgentes de liberalización del sector inmobiliario y de transportes, que suponen un cambio sustancial en el régimen del suelo no urbanizable, que pasa a tener la consideración de protegido y el urbanizable, que adquiere un carácter residual, al ser el que no queda protegido, en contra de ser un elemento de definición del modelo, como venía siendo antes.

Su aprobación se produce cuando ya un número importante de ayuntamientos han iniciado la adaptación, la revisión o nueva redacción de su planeamiento general a la ley 1997. Se inicia así un camino, en apariencia irreversible, si antes la tramitación de los planes se realizaba en dos años, ahora se pueden superar los diez y cuando nacen son totalmente inadecuados a la realidad que pretenden ordenar. La LOUG, como ya lo había hecho la de 1997, obligaba a adaptar el planeamiento en el plazo de dos años, sin discriminar municipios con nula complejidad urbanística o aquellos que la dinámica anterior a la crisis estaba transformando rápidamente, principalmente en relación con la vivienda y las tipologías demandadas.

La LOUG plantea una estructura similar a la de todas las leyes urbanísticas españolas, una clasificación del suelo ajustada a las clases tradicionales, incorporando el suelo urbano no consolidado y la ya reconocida clase de núcleo rural y las denominadas áreas de expansión, con la clara intención de reconducir el proceso edificatorio en los bordes de núcleo y la herencia dejada por el mal uso del suelo no urbanizable común. Se modificaba así el tratamiento del suelo de núcleo de la Ley de 1997 que permitía delimitaciones muy amplias. Se iba tomando conciencia de la necesidad de controlar la ocupación del suelo en un territorio especialmente valioso donde el planeamiento general suele proteger más del $70 \%$ de la superficie municipal, como suelo rústico, ya recuperado el término en la Ley de 1997, frente a no urbanizable. Básicamente esto es así dada la gran cantidad de superficie de montes en mano común, el gran número de cursos de agua, que otorgan una calidad paisajística importante, suponen un soporte de vida y garantizan el potencial de la explotación agrícola, que también se protege.

La LOUG no modifica de manera importante el régimen de suelo, a excepción del de núcleo para el que las determinaciones pasan a ser normativas, planteando casi 
unas ordenanzas vinculantes. A título de ejemplo se establecen condiciones de parcelación con carácter general sin tener en cuenta las grandes diferencias del tamaño de parcela entre unas zonas y otras. Además también insiste en las normas estéticas sin tener en cuenta la riqueza de la diversidad del patrimonio arquitectónico gallego.

Otro tanto ocurre con el suelo rústico para el que plantea un régimen de usos pormenorizado y una regulación para las reclasificaciones en el caso de incendios y la aparición del art. 206 en el que se restringe de manera notable la parcelación, sin duda con el objeto de evitar la reproducción histórica del minifundio. Más tarde se incorporará la posibilidad de la división de parcelas sin edificar, por razón de herencias, con la condición de no edificar los lotes resultantes y estos tengan más de $15.000 \mathrm{~m}^{2}$.

Siendo quizás el tema más relevantes desde le punto de vista de la ordenación la incorporación de los arts. 46. Límites de Sostenibilidad, 47. Calidad de Vida y Cohesión social y 48. Normas de Calidad Urbana. El 46 con un criterio limitado de lo que es la sostenibilidad, en un momento en que la Estrategia Territorial Europea (1999) ya planteaba la sostenibilidad como dependiente de tres factores: cohesión social, desarrollo económico y medio ambiente. Este artículo habla solo de edificabilidades a asignar para el suelo urbano no consolidado y urbanizable en función exclusivamente del número de habitantes, generalizando para toda Galicia, con independencia de la evolución urbanística histórica del municipio. Plantea la necesidad de mantener la trama urbana y que las nuevas edificaciones sean coherentes con la tipología arquitectónica característica.

En lo relativo a la gestión se introduce la permuta forzosa junto con los sistemas tradicionales, la ocupación directa ya había quedado incluida anteriormente. Como novedad introduce el Sistema de Concesión de Obra Urbanizadora, que pese a las sucesivas sentencias en relación con la Comunidad Valenciana y lo leonino de su condiciones sigue aún vigente, cabiendo esperar que no se ponga en marcha, dado lo injusto e inadecuado de su planteamiento en relación con el sistema de propiedad, en el que el número de propiedades impide acuerdos rápidos tanto en la gestión por sistemas convencionales como de reacción ante la iniciación de un sistema de este tipo. Madrid lo suprimió en su día.

En cuanto a la documentación la LOUG exige, como novedad, para los Planes Generales la realización de un Estudio de Sostenibilidad Ambiental, Territorial y Paisajística (ESATP). La trasposición de la directiva 42 y la entrada en vigor de la Ley 9/2006, de 28 de abril, de evaluación de determinados planes y programas en el medio ambiente, provoca la aparición de la Ley 6/2007, de 11 de mayo, de medidas urgentes en materia de ordenación del territorio y del litoral de Galicia que incorpora, a través de una artículo denominado Integración de Procedimientos, la necesidad de la Evaluación Ambiental Estratégica (EAE) y su tramitación conjunta con el planeamiento. Como no podía ser de otra manera, el ESATP desaparece en el Texto consolidado del 2012, no así su exigencia en el planeamiento de desarrollo cuando se ha declarado no necesaria la EAE, pero vaciado de contenido al desaparecer de la Ley.

Dos años después de la LOUG entra en vigor la Ley 15/2004, de 29 de diciembre de modificación de la LOUG, en su aprobación tiene mucho que ver, sin duda, la entrada en vigor de la Ley 10/2003, de 20 de mayo, de medidas urgentes de 
liberalización del sector inmobiliario y de transportes. La ley se aprueba con el objetivo de perfeccionar la LOUG: "con la finalidad de garantizar el acceso de la población a la vivienda, garantizar la sostenibilidad de los usos del territorio y fortalecer el sistema urbano y de asentamientos surales tradicionales procurando evitar la dispersión de la urbanización y la edificación sobre el territorio".

Modifica sustancialmente el régimen del suelo rústico y la definición de sus categorías, por ejemplo en el caso del protegido forestal en la LOUG, los "montes públicos y los montes en mano común" quedan incluidos en esa categoría y en la 15/2004 "los montes en mano común podrían ser calificados como suelo rústico de protección forestal". Para concluir con la desprotección de estos monte en la Ley $15 / 2010$, de 28 de diciembre, de medidas fiscales y administrativas, en la que en la nueva redacción no se mencionan, dando carta de naturaleza para su ocupación por diversos usos, ya sean industriales, infraestructuras o equipamientos como, de hecho, ya se venía permitiendo.

También la Ley 15/2004, introduce la posibilidad de "excluir de esa categoría las áreas sin masas arboladas merecedoras de protección, colindantes sin solución de continuidad con el suelo urbano o los núcleos rurales, que resulten necesarias para el desarrollo urbanístico racional", lo que se mantiene ignorando lo previsto en la Ley $3 / 2007$, de 9 de abril, de prevención y defensa de los incendios forestales. De nuevo aquí se modifican las condiciones generales de edificaciones en suelo de núcleo rural y rústico volviendo a incidir en temas normativos propios del carácter del planeamiento municipal.

Se mantiene el art.50. Normas Técnicas de Planeamiento, realmente necesarias en función de la dispersión de la calidad de las cartografías, la introducción de las técnicas digitales o la diversidad de interpretación de determinados términos de carácter general. Servirían para garantizar la calidad de los documentos y la coordinación entre municipio. Once años después siguen sin ponerse en marcha.

La irrupción de la crisis en el año 2007 y la entrada en vigor de la Ley Estatal, $8 / 2007$, de 28 de mayo, del suelo y su posterior texto refundido y la creación de la Consellería de Vivienda tiene mucho que ver con la aparición de la Ley 6/2008, de 19 de junio, de Medidas Urgentes en Materia de Vivienda y Suelo, por la que de nuevo se modifica la LOUG. En este momento se aprovecha para incorporar como cesión obligatoria "terrenos destinados a la dotación autonómica" para la construcción de viviendas de promoción y titularidad pública y establece una cuantía de $2,5 \mathrm{~m}^{2}$ de suelo por cada $100 \mathrm{~m}^{2}$ de edificación residencial, en el suelo urbanizable", norma que al igual que en Madrid ha quedado derogada, perdiéndose una oportunidad efectiva de intervención pública en materia de vivienda.

La Ley plantea, poniéndola en el artículo 47 como un factor de cohesión social, la exigencia de una reserva del $40 \%$ de la edificabilidad residencial en municipios de más de 20.000 habs., que como novedad', afecta no solo al suelo urbanizable sino también al suelo urbano no consolidado y será como mínimo el 30\% en los restantes municipios, ajustándose al mínimo establecido en la legislación estatal. La distribución de estos porcentajes se hará en función de unas reglas que la propia ley establece, amén de precisiones en los municipios de menos de 20.000 habs. La LOUG ya había establecido la necesidad de la reserva del $20 \%$ para el suelo no urbanizable. 
Dichas viviendas "se deberán localizar evitando la concentración excesiva de viviendas de dicho tipo, para favorecer la cohesión social y evitar la segregación territorial de los ciudadanos por su nivel de renta". En un intento de evitar al "guetificación" de épocas anteriores. Más adelante, en el Texto consolidado de 2012 se reduce, a un mínimo, el porcentaje al 30\% de la edificabilidad residencial del suelo que vaya a ser incluido en actuaciones de urbanización. Se plantean también unas reglas matemáticas para la estimación de la demanda potencial de vivienda protegida en función de distintos factores, entre los que figuran el estar inscrito como solicitante en el registro de demandantes, como es lógico, por la dificultad de su parametrización, no se tiene en cuenta la realidad social de cada municipio.

La ley incide en el destino y la constitución de los patrimonios públicos de suelo, señalando que no se pueden enajenar o permutar bienes del patrimonio público, en tanto no se haya constituido el patrimonio público y el registro de solares, se entiende que para atajar las prácticas anteriores, en las que el patrimonio público de suelo estaba muy lejos de ser utilizado para los fines de su constitución.

Tan solo dos años más tarde se aprueba la Ley 2/2010, de 25 de marzo, de Medidas Urgentes de Modificación de la LOUG, en esta ocasión con un primer objetivo de partida, atender a los ayuntamientos en sus inquietudes ante la imposibilidad de tramitación del planeamiento en unos plazos prudenciales y aprovecha para insistir en el perfeccionamiento del suelo de núcleo rural y del suelo rústico complejizándolo innecesariamente y vaciando de contenido una vez más al Plan General, común a todos los municipios una vez desaparecidas las Normas Subsidiarias Municipales, por las sucesivas vinculaciones del planeamiento a las determinaciones pormenorizadas de la ley.

Esta Ley afecta básicamente en la delimitación de los núcleos rurales, estableciendo tres categorías: histórico tradicionales, comunes y complejos, estos últimos como conjunto de los anteriores, con unas condiciones mucho más restrictivas en relación con las leyes anteriores, dejando fuera de ordenación viviendas construidas con licencia, lo que ha dificultado enormemente la adaptación de los planes aprobados anteriormente o aquellos que estaban tramitándose con la LOUG. Posteriormente se aprueba una instrucción, con el carácter limitado que ésta tiene pero asumida con generalidad, en la que la delimitación se convierte en una simple fórmula matemática que ignora la realidad de los asentamientos y su desarrollo tradicional.

A lo largo de la redacción de la legislación urbanística gallega se había manifestado una clara preocupación por la ordenación de los núcleos y así aquí aparecen los Planes Especiales de Ordenación del Núcleo Rural, en sustitución de los antes denominados Planes Especiales de Protección, Rehabilitación y Mejora del Medio Rural, a su vez herederos de los Planes Especiales de Mejora del Medio Rural de la Ley de 1997. Se considera un documento de ordenación urbanística pormenorizada del núcleo que se aproxima, cada vez más, a las características del suelo urbano, en cuanto a deberes y derechos, sin atender a las grandes diferencias económicas y sociales de los distintos municipios.

Se incorpora la memoria de sostenibilidad económica a la que obliga la ley estatal, pero no se aprovecha para adaptar los convenios a la misma o eliminarlos como si haría la legislación madrileña, en un momento en el que los temas de corrupción 
urbanística empiezan a ocupar los titulares de los periódicos. En ese mismo año aún habrá otra modificación importante aprovechando el cierre del año económico, la Ley 15/2010, de 28 de diciembre, de medidas fiscales y administrativas, sirve de nuevo para modificar el suelo rústico, y tratar de algunos temas relativos a la expropiación y parcelaciones.

El 26/09/2012 se publica el texto consolidado de la LOUG, estando en el 2015 pendiente de aprobación la nueva Ley. Es posible que el presente artículo no parezca más que una enumeración sucesiva de leyes, con el tratamiento parcial de algunos temas, pero entiendo que es suficiente para entender la incertidumbre en la que se mueve el planificador, al carecer de un marco legal estable, la situación no es diferente en Galicia de otras Comunidades Autónomas, donde el planeamiento se tramita y aprueba igualmente de forma limitada.

El planificador ha dejado de ser un profesional que se dedica a la ordenación urbanística a partir de una realidad existente en aplicación de unos criterios y objetivos establecidos previamente para pasar a moverse en el proceloso mar de la legislación urbanística y de la legislación sectorial que a modo de catarata se ha ido emitiendo, tanto desde el Estado como de las Comunidades Autónomas y receloso de meter la pata u olvidar alguna norma por el camino. Sin olvidar la complejidad de interpretación de todas las disposiciones adicionales y transitorias que la modificación de las leyes exigen y por tanto, acompañan a cada nueva norma.

No hay que olvidar que seguimos en Galicia, donde municipios con una escasa o nula complejidad urbanística se ven obligados a redactar un Plan General, en ausencia de unas Normas Subsidiarias Provinciales adaptadas, las últimas son de 1.991 y documento más que suficiente, utilizando recursos que serían mejor empleados en otras áreas. En su normativa de obligado cumplimiento incorporan un listado de 104 leyes, decretos, etc., de imposible seguimiento con los medios técnicos que disponen. O donde municipios más dinámicos costeros, con puerto, aeropuerto, ferrocarril y autopista como elementos añadidos requieren para su aprobación 36 informes sectoriales, caso de Redondela, que hay que coordinar entre sí y pueden ser favorables o no, pero vinculan, y por los que hay que esperar, no los plazos administrativos legales, sino hasta dos años, lo que conlleva la proliferación de modificaciones frente a la adaptación, revisión o redacción de nuevo planeamiento.

La inseguridad jurídica de una actividad con un alto contenido económico ha llevado a su judicialización, por las imprecisiones y los cambios sobrevenidos, las dudas en cuanto a la vinculación de las nuevas determinaciones al planeamiento vigente. Los contratos se rescinden por imposibilidad manifiesta de concluir los trabajos, trabajos sin aprovechamiento posible por la obsolescencia de los mismos dado el tiempo transcurrido, el incumplimiento generalizado de los plazos en los informes sectoriales y la posibilidad de la espada de Damocles de olvidar algo por el camino o un informe que no llega a tiempo. Todo ello ha convertido una profesión necesaria en un calvario, al parecer sin retorno, salvo que en algún momento alguien decida refundar el sistema adaptándolo a los nuevos tiempos llenos de retos, la sostenibilidad bien entendida, la globalización, la gobernanza... y se garantice la seguridad jurídica con normas claras y tramitaciones ajustadas. 